\title{
Heterologous microsatellite primers are informative for paca (Cuniculus paca), a large rodent with economic and ecological importance
}

\author{
Franco F. Roldán Gallardo ${ }^{1,2}$, Karen E. DeMatteo ${ }^{1,3,4}$, Miguel A. Rinas ${ }^{5}$ and Carina F. Argüelles ${ }^{1,2^{*}}$ (D)
}

\begin{abstract}
Objective: This study was designed to facilitate genetic studies that would allow information on population structure and genetic diversity of natural or captive stocks of paca (Cuniculus paca), a species of ecological and socioeconomic importance, by testing cross-amplification of 20 heterologous microsatellite primer pairs developed for guinea pigs (Cavia porcellus) and capybara (Hydrochoerus hydrochaeris).

Results: Those primers that showed the best amplification profile in blood samples were subsequently applied to scats and saliva samples, to evaluate their efficiency. Of the 13 microsatellite pairs that amplified in blood, one-third (32\%) were successfully amplified in saliva and scat samples. This initial work demonstrates successful cross-amplification in paca providing a solid and promising foundation for future genetic studies with this species. The ability to quantify genetic diversity using noninvasive samples from free-ranging paca is essential to developing applied management strategies for this large neotropical rodent that is not only a prey favored by wide-ranging carnivores [e.g., jaguar (Panthera onca), puma (Puma concolor)], but is also a species targeted by illegal hunting and wildlife trade.
\end{abstract}

Keywords: Cuniculus paca, Heterologous amplification, Microsatellite primers, Saliva, Scat

\section{Introduction}

The paca (Cuniculus paca, Linnaeus, 1766), a grounddwelling, herbivorous rodent, is a unique genus in the family Cuniculidae. The paca is the second largest neotropical rodent with a broad distribution across Central and South America from Mexico to northeast Argentina, with recent introductions in Cuba and the Lesser Antilles $[1,2]$. The species inhabits a wide range of humid tropical forests, preferring places near rivers or streams, but can also be found in grasslands, mangrove swamps,

\footnotetext{
*Correspondence: franciscarguelles@yahoo.com

1 Facultad de Ciencias Exactas, Químicas y Naturales, Departamento de Genética, Universidad Nacional de Misiones (UNaM), Posadas, Misiones, Argentina

Full list of author information is available at the end of the article
}

and agricultural areas [3]. This medium-sized animal $(6-14 \mathrm{~kg})$ is nocturnal, solitary, territorial, monogamous, and sedentary [4]. While it can be vector of zoonotic diseases (e.g., intermediate hosts for Echinococcus vogeli; [5]), it is susceptible to others (e.g., leishmaniasis, trypanosomiasis; [2]).

The paca is a favored prey of many carnivores [e.g., coyote (Canis latrans), puma (Puma concolor), jaguar (Panthera onca), bush dog (Speothos venaticus)], crocodiles, and heavy-bodied snakes [e.g., boa constrictor (Boa constrictor)], among others [2]. Furthermore, it is consumed by human beings, who have targeted this species for its quality meat [6], which is even desired by restaurants [7]. Nevertheless, paca is classified as Least Concerned by the IUCN due to its broad distribution, presumed large populations, and occurrence in protected areas [1]. However, habitat

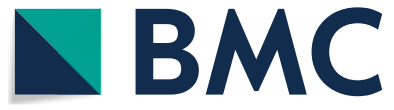

(c) The Author(s) 2020. This article is licensed under a Creative Commons Attribution 4.0 International License, which permits use, sharing, adaptation, distribution and reproduction in any medium or format, as long as you give appropriate credit to the original author(s) and the source, provide a link to the Creative Commons licence, and indicate if changes were made. The images or other third party material in this article are included in the article's Creative Commons licence, unless indicated otherwise in a credit line to the material. If material is not included in the article's Creative Commons licence and your intended use is not permitted by statutory regulation or exceeds the permitted use, you will need to obtain permission directly from the copyright holder. To view a copy of this licence, visit http://creativeco mmons.org/licenses/by/4.0/. The Creative Commons Public Domain Dedication waiver (http://creativecommons.org/publicdomain/ zero/1.0/) applies to the data made available in this article, unless otherwise stated in a credit line to the data. 
fragmentation or destruction and hunting have led to local extinctions in the southeast portion of its distribution [8]. Consequently, genetic studies are needed to monitor the species' status, since directed conservation efforts may be needed to ensure their long-term survival.

Genetic analyses with molecular markers are needed to reveal genetic variability at the species and individual level; however, no species-specific microsatellite primers have been developed for the paca. Microsatellites or STRs /SSRs (Short Tandem Repeats / Single Sequence Repeats) are one of the most widely and versatile genetic markers used in molecular ecology to address questions about the conservation and management of threatened and endangered species $[9,10]$. The ability to use these markers on noninvasive samples (e.g., scat) removes the need to capture animals directly (e.g., live traps) or indirectly (e.g., camera traps) and focuses on evidence left behind on the animal's daily movements $[11,12]$. While some believe primers designed for a particular species may not be able to amplify the same loci in other phylogenetically-related individuals unless the flanking regions, where the primers hybridize, are highly conserved $[13,14]$, others suggest this can occur more often than initially thought [15-18].

The ability to use heterologous primers developed for a closely related species has removed limits when speciesspecific primers are lacking and allowed researchers to quickly expand studies to new species [19, 20]. Crossamplification has been applied several times at the interface of domestic and free-ranging animals, including the application of domestic cat microsatellite primers to wild cats [11], canid-specific gender identification primers to bush dogs [21, 22], and domestic pig microsatellite primers to wild peccary [23].

Given the lack of species-specific primers for paca, this study drew 20 primers from 34 heterologous primers developed for the superfamily Caviodidea, which the paca shares with guinea pigs (Cavia porcellus; [24]) and capybara (Hydrochoerus hydrochaeris; [25, 26]). The 20 evaluated primer pairs were selected because they had an expected amplicon size of $<300$ bp (range 106-289 bp; [24, 26]). While initial testing of cross-amplification would be done with invasive samples (e.g., blood, saliva), the long-term goal is to have the selected primers work with noninvasive samples or forensic DNA from free-ranging populations, including in the biological corridor proposed for northerncentral zone of Misiones, Argentina [27].

\section{Main text \\ Methods}

\section{Sample collection}

Blood, buccal swabs, and scats samples were obtained from three individual paca held at the breeding center of the Instituto Nacional de Tecnología Agropecuaria
(INTA) in Aristóbulo del Valle, Misiones, Argentina. All sample collection was conducted by a licensed veterinarian. Sample collection protocols were approved by the Ministerio de Ecología y Recursos Naturales Renovables (MEyRNR) in accordance with Law No 47, Regulatory Decree No 474/02, and Resolution No 509/07 of Misiones Province. Collection permits were granted through the Directorate of Ecology and Environmental Quality under Provision No 033, which relates to the handling of animals and collection of samples.

Each paca was captured using a net and manually held in position. Blood and buccal swabs samples were taken after the animal was anesthetized using $6.5 \mathrm{mg} / \mathrm{kg}$ Zela$\mathrm{zol}^{\circledR}$ (Fort Dodge, Tiletamine-Solazepan). For each paca, $3 \mathrm{~mL}$ of blood was extracted from the radial vein and collected in polypropylene tubes anticoagulated with 5\% Ethylenediaminetetraacetic Acid (EDTA) and maintained at $-20^{\circ} \mathrm{C}$ until subsequent treatments. In addition, three sterile buccal swabs were collected and placed in individually labeled envelopes where they were allowed to air dry prior to storage at room temperature. Finally, six scat samples were collected from their cages, with each sample potentially representing multiple individuals, as two pacas were housed in the enclosure. Scat surfaces were swabbed in triplicate with a cotton-tipped applicator soaked in $1 \times$ phosphate buffered saline solution to obtain cells detached from the animal's intestinal epithelium $[28,29]$. Each of these swabs was placed in a $2 \mathrm{~mL}$ polypropylene tube and maintained at $-20{ }^{\circ} \mathrm{C}$ until DNA extractions were carried out. Scat samples were placed in an individually, labeled plastic bag (18-oz Whirlpak ${ }^{\circledR}$ bagNasco, Fort Atkinson, WI) and maintained at $-20^{\circ} \mathrm{C}$, as a backup for DNA extractions.

\section{Genetic analyses}

DNA was extracted using Cetyl Trimethyl Ammonium Bromide (CTAB) following the corresponding extraction protocol for each sample type [30]. DNA integrity was evaluated in $1 \%$ agarose (Invitrogen ${ }^{\mathrm{TM}}$ ) gel and stained with GelRed ${ }^{\mathrm{TM}}$ (Biotium).

Of 34 potential primer pairs, 20 that would yield $<300$ bp amplicons were selected for cross-amplification testing in paca; 12 developed for guinea pigs $(C$. porcellus; [24]; Table 1$)$ and 8 developed for capybara $(H$. hydrochaeris; [26]; Table 1). All primers sets were synthesized by $\mathrm{IDT}^{\circledR}$ (USA) and each primer pair was optimized independently. Amplification assays were conducted in a Perkin Elmer GeneAmp System 9600 thermal cycler (Applied Biosystems) in a $25 \mu \mathrm{L}$ and $15 \mu \mathrm{L}$ of final reaction volume for the primers developed for guinea pigs and capybara respectively, containing $1 \times{\text { Green } \text { GoTaq }^{\circledR}}^{\circledR}$ Flexi Buffer, $2.0 \mathrm{mM}$ (guinea pig) and $1.5 \mathrm{mM}$ (capybara) of $\mathrm{MgCl}_{2}, 0.2 \mu \mathrm{M}$ of each primer (forward and reverse), 
Table 1 Details of the 20 microsatellite primer pairs tested for cross-amplification in paca

\begin{tabular}{|c|c|c|c|c|c|}
\hline ID & Sequence $\left(5^{\prime}\right.$ to $\left.3^{\prime}\right)$ & Repeat motif & $\mathrm{Ta}\left({ }^{\circ} \mathrm{C}\right)$ & Size range (bp) & References \\
\hline \multirow[t]{2}{*}{ CUY5 } & F: GGCCAAAGCAGGAATGTCTA & CA & 55 & $141-163$ & Aviles et al. [24] \\
\hline & R:TAGGGCAAGCATTGATGATG & & & & \\
\hline \multirow[t]{2}{*}{ CUY6* } & F:TGGCTTGCTTTCTCTTTGGT & CA & 55 & $158-168$ & \\
\hline & R: CTGTGCTCAGCATTGCATTT & & & & \\
\hline \multirow[t]{2}{*}{ CUY7 } & F: GATGCAGTGCAGAGGAGTCA & CA & 55 & $183-197$ & \\
\hline & R:TGTGTGGTTTTGTGTGTGAGG & & & & \\
\hline \multirow[t]{2}{*}{ CUY8* } & F:TGATTGCACCTGAGAAGTGG & $\mathrm{TC}$ & 55 & $181-217$ & \\
\hline & R: CCAAGTGTTCTTGGTGCTTG & & & & \\
\hline \multirow[t]{2}{*}{ CUY9 } & F: GCTGGAATGCAAGACAAGC & GT & 55 & $116-130$ & \\
\hline & R:TGAGTTTTCAGCTGTGATGAGT & & & & \\
\hline \multirow[t]{2}{*}{ CUY10* } & F:TTCCAAGCATTTCAGAAAACA & GT & 55 & $106-128$ & \\
\hline & R:TGACTTCCCAACCAAGGAAA & & & & \\
\hline \multirow[t]{2}{*}{ CUY17 } & F:TGATGGACAATATACTGGGAACC & TC & 55 & $152-170$ & \\
\hline & R:TAGCATGCATGAAGCCCTAA & & & & \\
\hline \multirow[t]{2}{*}{ CUY18* } & F:TGTCACTTCTCACTCCACCA & CA & 55 & $176-214$ & \\
\hline & R:TCCCAAACCTCTTGTTTGCT & & & & \\
\hline \multirow[t]{2}{*}{ CUY22 } & F: CGAACATGCCAAGCAGATTA & TC & 55 & $206-232$ & \\
\hline & R: ACACCAGTTCCTTGCCACAT & & & & \\
\hline \multirow[t]{2}{*}{ CAVY2 } & F: GGCCATTATGCCCCCCAAC & $A C$ & 55 & $124-154$ & \\
\hline & R: AGCTGCTCCTTGTGCTGTAG & & & & \\
\hline \multirow[t]{2}{*}{ CAVY11* } & F: CCGTGCTTTTCCTGTCTTTG & $\mathrm{CT}$ & 55 & $140-180$ & \\
\hline & R:TGGACCCCAATCTGACATAG & & & & \\
\hline \multirow[t]{2}{*}{ CAVY12 } & F: AGAATGCCTTTGGGACTGG & $A G$ & 55 & $143-187$ & \\
\hline & R: AGATCTTGCCTCTGCACTTG & & & & \\
\hline \multirow[t]{2}{*}{ CAPY ${ }^{*}$} & F: GGAATTCCAAAAGACAACAGTTA & (GT)12 & 59 & 185 & Herrera et al. [26] \\
\hline & R:TCTCTCCTCAAAACAACAACAGA & & & & \\
\hline \multirow[t]{2}{*}{ CAPY4 } & F: ACACAGGTGCATTTGGCATA & (GT)12 & 60 & 190-192 & \\
\hline & R: ATGAGGATGTGGCAGAAAGG & & & & \\
\hline \multirow[t]{2}{*}{ CAPY6 } & F: ATGGGGACTCCAGCAAGTTA & (GT)5AT-(GT)7 & 56 & 289 & \\
\hline & R: AGATACATGCCTTCCCCAAA & & & & \\
\hline \multirow[t]{2}{*}{ CAPY7* } & F: CCTCAACATCCGTTTTCCTC & (GT)16 & 60 & $272-278$ & \\
\hline & R: CCCAAGGGTTGAAACACAGT & & & & \\
\hline \multirow[t]{2}{*}{ CAPY9 } & F:TGCCATTCTTGTGAAAGGTG & (GT)17 & 60 & $152-162$ & \\
\hline & R:TGCCCGTTTCAGTGTGTACT & & & & \\
\hline \multirow[t]{2}{*}{ CAPY10 } & F: CAAGGCTTCTGCTCACTCATT & $(\mathrm{GCT}) 9$ & 56 & 182 & \\
\hline & R:TGAGGCATGCAAGAGCAA & & & & \\
\hline \multirow[t]{2}{*}{ CAPY12 } & FTGGGTGCCAGAATGCATAGTC & (GT)10 & 61 & 195-197 & \\
\hline & R: GCATTGCCACCCCTACCTTA & & & & \\
\hline \multirow[t]{2}{*}{ CAPY24 } & F:TGCAGGGAGCACTTTATCCA & (GT)7-TT-(GT)8 & 54 & $145-157$ & \\
\hline & R: CAAGCTGGGCACAAAAAGGA & & & & \\
\hline
\end{tabular}

The 12 primer pairs developed for guinea pigs (Aviles et al. [24]) and the 8 primer pairs developed for capybara (Herrera et al. [26]) are detailed in the table. Reported for each primer are the identification (ID), the forward primer sequence (F), the reverse primer sequence (R), the published annealing temperature (Ta), the published expected fragment size (bp), and original reference for these primers. An "** highlights the seven of heterologous primer pairs that could not be consistently scored and interpreted. The repeat motif numbers were not reported in Aviles et al. [24]

$0.2 \mathrm{mM}$ of each dNTP, $150 \mu \mathrm{g} / \mathrm{mL}$ Bovine Serum Albu-

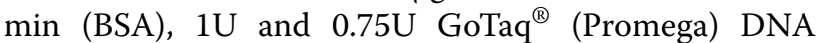
Polymerase, and $2 \mu \mathrm{L}$ of DNA. Negative controls were included in all assays. For those primers used in capybara [26], the published annealing temperatures $\left(T_{a}\right)$ were used as a starting point in the cross-amplification tests with paca (Table 2), but were adjusted to maximize amplification efficiency.

Amplification success was initially verified in 3\% agarose gels using the previously described technique, 
except for $50 \mathrm{~min}$ at $5 \mathrm{~V} / \mathrm{cm}$. For allele discrimination, amplicons were analyzed using $6 \%$ vertical electrophoresis denaturing polyacrylamide gels (acryl:bisacrylamide 32:2) including a 25 bp DNA Ladder (Invitrogen ${ }^{\mathrm{TM}}$ ) as a molecular marker in $0.5 \times \mathrm{TBE}$ for $90 \mathrm{~min}$ at $60 \mathrm{~W}$. Gels were stained with Silver Sequence ${ }^{\mathrm{TM}}$ Staining Reagent kit (Promega) and digitally documented with Kodak EasyShare Z7590 camera.

To confirm successful cross-amplification of microsatellite regions in paca, three amplicons, obtained from blood samples, were randomly selected to be sequenced through the Sanger methodology at Macrogen, Inc. Korea.

\section{Results}

Thirteen $(65.0 \%)$ of heterologous primers pairs amplified DNA extracted from blood (100\% of samples), saliva (46.2\% of samples), and scat (20.5\% of samples), while seven $(35.0 \%)$ of heterologous primers pairs could not be consistently scored and interpreted (Table 1). Seven (53.9\%) of the microsatellite primers pairs that successfully cross-amplified in paca were from the twelve developed for guinea pigs (CUY5, CUY7, CUY9, CUY17, CUY22, CAVY2, and CAVY12; Table 1). The remaining six (46.2\%) successful primers were from the eight described for capybaras (CAPY4, CAPY6, CAPY9, CAPY10, CAPY12, and CAPY24; Table 1). The efficiency of the cross-amplification in paca was verified with capillary electrophoresis on an ABI3130XL (Macrogen, Inc) that compared the expected repeat motif for each primer pair in three randomly selected primers (CUY7, CUY9, and CAPY24; Table 1); however, sequences could not be uploaded to GenBank due to the fact all were $<200 \mathrm{bp}$ in size or below the minimum size required by this service.
Thirteen $(65.0 \%)$ of the tested loci in paca produced amplicon size ranges similar to those in the two species (guinea pig and capybara) for which the primers were originally developed (Table 3 ). Three primers (CAVY2, CAVY12, and CAPY9) had amplicons that fell within the published ranges for guinea pig and capybara. Eight primers (CUY7, CUY9, CUY17, CAPY4, CAPY6, CAPY10, CAPY12 and CAPY24) had amplicons that showed light shifts ( \pm 1 to $49 \mathrm{bp}$ ) from the expected size ranges. Two primers (CUY5 and CUY22) had amplicons that showed larger shifts $( \pm 43-130 \mathrm{bp})$ from the published size ranges. In addition, while two primers (CAPY6 and CAPY10) were published as homozygous in capybara, both were heterozygous in paca. All 13 (100\%) of these amplified loci were polymorphic (range: 2-6 loci), showing different sized loci (Table 3 ).

\section{Discussion}

Using heterologous primers, we identified 13 microsatellite primers pairs that will facilitate future studies focused on identifying individual paca from scat or other noninvasive, fragmented DNA sources. Gaining genetic information from noninvasive samples has increased the amount of information that can be obtained [31], especially in the field of conservation. It also allows insight into species distribution [32,33], habitat preferences and requirements [34, 35], and diet [36, 37]. Expanding this to the individual-level provides knowledge on gender identification and population ratios $[38,39]$, species abundance $[40,41]$, and population density $[42,43]$. Together, these genetic data can be used to investigate broader population-level questions including rates of gene flow $[44,45]$, genetic diversity $[46,47]$, and phylogeographic studies [35, 48].

Table 2 Summary of the PCR profiles for cross-amplification of microsatellites in paca using 20 heterologous primer pairs developed for guinea pigs and capybara

\begin{tabular}{|c|c|c|c|c|c|}
\hline \multirow[t]{2}{*}{ PCR step } & \multirow{2}{*}{$\begin{array}{l}\text { Guinea pig } \\
\text { All }\end{array}$} & \multicolumn{4}{|l|}{ Capybara } \\
\hline & & CAPY1 & CAPY9 and CAPY 24 & $\begin{array}{l}\text { CAPY 4, CAPY6, CAPY7, } \\
\text { and CAPY10 }\end{array}$ & CAPY12 \\
\hline Initial denaturation & $95^{\circ} \mathrm{C}$ for $5 \mathrm{~min}$ & $95^{\circ} \mathrm{C}$ for $5 \mathrm{~min}$ & - & - & - \\
\hline \# of cycles & 34 & 34 & - & -- & - \\
\hline Denaturation & $95^{\circ} \mathrm{C}$ for $40 \mathrm{~s}$ & $94{ }^{\circ} \mathrm{C}$ for $30 \mathrm{~s}$ & - & & - \\
\hline Annealing & $55^{\circ} \mathrm{C}$ for $30 \mathrm{~s}$ & $53{ }^{\circ} \mathrm{C}$ for $30 \mathrm{~s}$ & $54{ }^{\circ} \mathrm{C}$ for $30 \mathrm{~s}$ & $55^{\circ} \mathrm{C}$ for $30 \mathrm{~s}$ & $57^{\circ} \mathrm{C}$ for $30 \mathrm{~s}$ \\
\hline Elongation & $72{ }^{\circ} \mathrm{C}$ for $40 \mathrm{~s}$ & $72{ }^{\circ} \mathrm{C}$ for $40 \mathrm{~s}$ & - & - & - \\
\hline Final extension & $72^{\circ} \mathrm{C}$ for $5 \mathrm{~min}$ & $72^{\circ} \mathrm{C}$ for $30 \mathrm{~min}$ & - & - & - \\
\hline Maintenance & $4^{\circ} \mathrm{C}$ & $4^{\circ} \mathrm{C}$ & - & - & - \\
\hline
\end{tabular}

All guinea pig primers $n=12$ (CUY5, CUY6, CUY7, CUY8, CUY9, CUY10, CUY17, CUY18, CUY22, CAVY2, CAVY11, and CAVY12; Aviles et al. [24] had the same PCR protocol. While capybara primers $n=8$ (CAPY1, CAPY4, CAPY6, CAPY7, CAPY9, CAPY10, CAPY12 and CAPY24; Herrera et al. [26]) had similar conditions across the majority of the PCR profile, indicated by "-" in the table, they varied in annealing temperature 
Table 3 Allelic details for the 13 microsatellite primer pairs that successfully cross-amplified in paca

\begin{tabular}{|c|c|c|c|c|c|c|c|c|c|c|c|c|c|}
\hline Primers & B1 & B2 & B3 & S1 & $\mathrm{S} 2$ & S3 & Scat 1 & Scat 2 & Scat 3 & Scat 4 & Scat 5 & Scat 6 & Total \\
\hline \multicolumn{14}{|l|}{ Guinea pig } \\
\hline CUY5 & $204 ; 204$ & $204 ; 202$ & $204 ; 202$ & $204 ; 204$ & $204 ; 204$ & $204 ; 202$ & - & - & & $206 ; 206$ & - & - & 3 \\
\hline CUY7 & $194 ; 186$ & $194 ; 186$ & $194 ; 186$ & $194 ; 186$ & $194 ; 186$ & $194 ; 186$ & $194 ; 186$ & $198 ; 182$ & $192 ; 192$ & $192 ; 192$ & - & $192 ; 188$ & 6 \\
\hline CUY9 & $138 ; 138$ & $144 ; 142$ & $142 ; 140$ & $138 ; 138$ & $144 ; 142$ & $142 ; 140$ & $140 ; 140$ & - & - & - & $138 ; 138$ & -- & 4 \\
\hline CUY17 & $174 ; 162$ & $174 ; 164$ & $172 ; 162$ & - & - & - & - & - & - & - & - & -- & 4 \\
\hline CUY22 & $102 ; 102$ & $102 ; 102$ & $102 ; 100$ & - & - & - & - & - & - & - & - & -- & 2 \\
\hline CAVY2 & $146 ; 142$ & $146 ; 142$ & $146 ; 142$ & $146 ; 142$ & - & - & - & - & - & - & - & - & 2 \\
\hline CAVY12 & $160 ; 158$ & $160 ; 158$ & $160 ; 158$ & $160 ; 158$ & - & - & - & - & - & $162 ; 160$ & - & - & 3 \\
\hline Capybara & & & & & & & & & & & -- & -- & \\
\hline CAPY4 & $172 ; 172$ & $172 ; 172$ & $172 ; 172$ & $172 ; 172$ & $170 ; 168$ & $170 ; 170$ & $170 ; 168$ & $170 ; 168$ & - & - & - & - & 3 \\
\hline CAPY6 & $266 ; 246$ & $266 ; 246$ & $268 ; 248$ & - & - & - & - & - & - & - & - & - & 4 \\
\hline CAPY9 & $154 ; 154$ & $154 ; 154$ & $156 ; 156$ & - & - & - & - & - & - & - & - & - & 2 \\
\hline CAPY10 & $216 ; 208$ & $216 ; 208$ & $216 ; 208$ & $216 ; 208$ & - & - & $208 ; 206$ & - & - & - & - & - & 3 \\
\hline CAPY12 & $246 ; 198$ & $246 ; 198$ & $242 ; 194$ & - & - & - & - & - & - & - & - & - & 4 \\
\hline CAPY24 & $120 ; 116$ & $122 ; 118$ & $120 ; 116$ & $120 ; 116$ & $122 ; 118$ & $120 ; 116$ & $124 ; 118$ & $120 ; 116$ & - & - & $118 ; 114$ & $118 ; 116$ & 6 \\
\hline
\end{tabular}

Specific sizes (bp) and total number of alleles (Total) are reported for each primer across the three blood samples (BI, BII, and BIII), three saliva samples (S1, S2, and S3), and six scat samples (Scat1, Scat2, Scat3, Scat4, Scat5 and Scat6). The thirteen pair of primers were polymorphic. No data is indicated by "-"

To confirm successful cross-amplification of microsatellite primers in paca, two different approaches were used. First, the Sanger sequencing results of three amplicons obtained using CUY7, CUY9, and CAPY24 showed that sequences matched the expected repeat motif published for microsatellite primers developed for guinea pigs and capybara. For paca, guinea pig primers CUY7 and CUY9 shared the repeat motif sequence (CA) and (GT), respectively. With capybara primer CAPY24, the sequence showed the same (GT) repeat motif, with the exception that paca lacked the (TT) interruption. Second, amplification results for blood and saliva were compared within individuals for consistency. Again, in all cases, allele sizes matched. It was not possible to compare similarities between blood and saliva with scat, as the latter represented a mixed sample from multiple pacas versus single individual. Therefore, the scat samples often represented different allelic combinations compared to the blood and saliva (Table 3).

Not surprisingly, amplification was not possible in all scat samples. This variation can be attributed to several factors including the presence of inhibitors in the extracted DNA, low concentrations of extracted DNA, and extremely fragmented or degraded DNA [31, 40, 49-52]. All of the primers $(n=13$ or $100 \%)$ tested in this study were polymorphic, which permits individuals in a population to be differentiated. It is suspected these primers would be even more informative in a free-ranging paca study, as those populations would likely have higher genetic variability compared to captive populations [53-55]. The low number of founders in the used captive population would suggest it likely possesses some levels of homozygosity (e.g., revealed by monomorphic microsatellites) and low genetic variability [56]. However, we cannot rule out that the low level of STRs variability observed in some primers might be a result of allelic dropout because the heterologous status of the primers used or allele fixation in the population due to inbreeding [57].

Additional work is needed in free-ranging paca populations to determine the number of microsatellite loci needed to distinguish among individuals, a number that varies depending on the population's genetic variability and the expected loci heterozygosity [49]. The number of loci needed must fit a balance between achieving the lowest probability of individual identity, while minimizing costs and using the lowest number of loci needed [58]. It is clear from these data on captive paca that the selection of loci that allows individuals to be identified with certainty can be a difficult task in small populations that have suffered bottlenecks in genetic variability due to genetic drift [31]. The 13 heterologous primers confirmed to successfully cross-amplify in paca are the first step to understanding genetic variability in free-ranging paca, which can form the foundation for applied management strategies for this large rodent that is favored by predators and humans alike.

\section{Limitations}

- The number of individuals used in the sampling was low and would ideally be expanded; however, INTA captive breeding centre limited the number authorized for use in this study. 
- The low number of founders in the INTA captive population likely limited genetic variability seen among the 13 proposed primer pairs.

- Testing of primer cross-amplification used exclusively captive individuals due to difficulty in obtaining invasive sample from free-ranging individuals.

\section{Abbreviations}

BSA: Bovine serum albumin; CTAB: Cetyl trimethyl ammonium bromide; DNA: Deoxyribonucleic acid; EDTA: Ethylenediaminetetraacetic acid; INTA: Instituto Nacional de Tecnología Agropecuaria; MEyRNR: Ministerio de Ecología y Recursos Naturales Renovables; SSR: Single sequence repeats; STR: Short tandem repeats; TBE: Tris borate EDTA; UV: Ultraviolet.

\section{Acknowledgements}

Not applicable.

\section{Authors' contributions}

All authors were involved with the designed the study. FFRG and MR collected samples used in this study. FFRG conducted genetic analyses with supervision and guidance from KD and CFA. All authors were involved with analysis of this study and development of resulting paper. All authors read and approved the final manuscript.

\section{Funding}

It was provided to Proyecto Zorro Pitoco by the Conservation, Food, \& Health Foundation, Eppley Foundation for Research, and Georgia AAZK. FFRG was supported by a CEDIT "Iniciación en la investigación; jóvenes estudiantes avanzados" scholarship.

\section{Availability of data and materials}

The datasets generated and/or analysed during the current study are not publicly available, as the sequences output sizes were $<200 \mathrm{bp}$, which is lower than the minimum length accepted by GenBank. Nevertheless, the datasets are available from the corresponding author on reasonable request.

\section{Ethics approval and consent to participate}

The INTA captive center, located in Aristóbulo del Valle and owned by Fabián Ruff, provided access for paca reference samples. All sample collection was conducted by a licensed veterinarian. Sample collection protocols were approved by the Ministerio de Ecología y Recursos Naturales Renovables (MEyRNR) in accordance with Law No 47, Regulatory Decree No 474/02, and Resolution No 509/07 of Misiones Province. Collection permits were granted through the Directorate of Ecology and Environmental Quality under Provision No 033 , which relates to the handling of animals and collection of samples.

\section{Consent for publication}

Not applicable.

\section{Competing interests}

The authors declare that they have no competing interests.

\section{Author details}

${ }^{1}$ Facultad de Ciencias Exactas, Químicas y Naturales, Departamento de Genética, Universidad Nacional de Misiones (UNaM), Posadas, Misiones, Argentina. ${ }^{2}$ Grupo de Investigación en Genética Aplicada (GIGA), Instituto de Biología Subtropical (IBS) - Nodo Posadas, UNaM - CONICET, Posadas, Misiones, Argentina. ${ }^{3}$ Department of Biology \& Environmental Studies, Washington University in St. Louis, St. Louis, MO, USA. ${ }^{4}$ WildCare Institute at the Saint Louis Zoo, St. Louis, MO, USA. ${ }^{5}$ Ministerio de Ecología y Recursos Naturales Renovables, Posadas, Misiones, Argentina.

Received: 12 April 2020 Accepted: 28 September 2020 Published online: 07 October 2020

\section{References}

1. Emmons L. Cuniculus paca.The IUCN Red list of threatened species. 2016. https://doi.org/10.2305/IUCN.UK.2016-2.RLTS.T699A22197347.en. Accessed 01 Mar 2016.

2. Patton JL, Pardiñas UFJ, D'Elía G. Family Cuniculidae. In: Patton JL, Pardiñas UFJ, D'Elía G, editors. Mammals of South America II: rodents. Chicago: University of Chicago Press; 2015. p. 726-733.

3. Aquino R, Gil D, Pezo E. Aspectos ecológicos y sostenibilidad de la caza del majás (Cuniculus paca) en la cuenca del río Itaya. Amazonía peruana Rev Peru Biol. 2009;16(1):67-72.

4. Ramírez O, Hernández-Santín L. Nuevos registros de tepezcuincle (Cuniculus paca) en Puebla, centro de México. Rev Mex Biodivers. 2012;83:872-4

5. Vizcaychipi KA, Rinas M, Irazu L, Miyagi A, Argüelles CF, DeMatteo KE. Neotropical zoonotic parasites in bush dogs (Speothos venaticus) from upper Parana Atlantic forests in Misiones. Argentina Vector Borne Zoonotic Dis. 2016;16(10):664-72

6. Deutsch LA, Puglia LLR. Os animais silvestres: Proteção, doenças e manejo. Publicações Globo Rural; 1988.

7. Moreira JR, Macdonald DW. Técnicas de manejo de capivaras e outros grandes roedores na Amazônia. Manejo e Conservação de Vida Silvestre no Brasil, Belém. Brasil: Sociedade Civil Mamirauá; 1997. p. 186-213.

8. Queirolo D, Vieira E, Emmons L, Samudio R. Cuniculus paca. In: IUCN 2012 (On-line) IUCN Red List of Threatened Species. 2012. https://doi. org/10.2305/IUCN.UK.2008.RLTS.T699A13068075.en. Accessed 30 June 2008.

9. Rowe G, Sweet M, Beebee TJC. An introduction to molecular ecology. 3rd ed. Oxford: Oxford University Press; 2017.

10. González EG. Microsatélites: Sus aplicaciones en la conservación de la biodiversidad. Graellsia. 2003;59(2-3):377-88.

11. DeMatteo KE, Rinas MA, Arguelles CF, Holman BE, Di Bitetti MS, Davenport $B$, et al. Using detection dogs and genetic analyses of scat to expand knowledge and assist felid conservation in Misiones. Argentina Integr Zool. 2014;9(5):623-39.

12. DeMatteo KE, Rinas MA, Argüelles CF, Zurano JP, Selleski N, Di Bitetti MS, et al. Noninvasive techniques provide novel insights for elusive bush dog (Speothos venaticus). Wildl Soc Bull. 2014;38(4):862-73.

13. FitzSimmons NN, Moritz C, Moore SS. Conservation and dynamics of microsatellite loci over 300 million years of marine turtle evolution. Mol Biol Evol. 1995:12(3):432-40.

14. Ellegren H. Polymerase-Chain-Reaction (PCR) analysis of microsatellites: a new approach to studies of genetic relationships in birds. Auk. 1992;109(4):886-95.

15. Pepin L, Amigues $Y$, Lepingle A, Berthier JL, Bensaid A, Vaiman D. Sequence conservation of microsatellites between Bos taurus (cattle), Capra hircus (goat) and related species. Examples of use in parentage testing and phylogeny analysis. Heredity. 1995;74(1):53-61.

16. Primmer CR, Moller AP, Ellegren $\mathrm{H}$. A wide-range survey of cross-species microsatellite amplification in birds. Mol Ecol. 1996;5(3):365-78.

17. Hoffmann GS, Johannesen J, Griebeler EM. Species cross-amplification, identification and genetic variation of 17 species of deer (Cervidae) with microsatellite and mitochondrial DNA from antlers. Mol Biol Rep. 2014:42(6):1059-67.

18. Da Silva HE, Presti FT, Wasko AP, Pinhal D. Development of microsatellite markers for Hyacinth macaw (Anodorhynchus hyacinthinus) and their cross-amplification in other parrot species. BMC Res Notes. 2015;8(1):736.

19. Parker PG, Snow AA, Schug MD, Booton GC, Fuerst PA. What molecules can tell us about populations: choosing and using a molecular marker. Ecology. 1998;79(2):361-82.

20. Abdul-Muneer PM. Application of microsatellite markers in conservation genetics and fisheries management: recent advances in population structure analysis and conservation strategies. Genet Res Int. 2014. https ://doi.org/10.1155/2014/691759.

21. DeMatteo KE, Parker PG, Eggert LS. Characterization of dinucleotide microsatellite loci and confirmation of sexing primers for the bush dog (Speothos venaticus). Mol Ecol Resour. 2009;9(4):1219-20.

22. DeMatteo KE, Rinas MA, Sede MM, Davenport B, Argüelles C, Lovett K, et al. Detection dogs: an effective technique for bush dog (Speothos venaticus) surveys. JWildl Manage. 2009;73(8):1436-40. 
23. Silva RW, de Freitas TR, Sbalqueiro IJ. Evaluation of genetic variability in the collared peccary Pecari tajacu and the white-lipped peccary Tayassu pecari by microsatellite markers. Genet Mol Biol. 2010;33(1):62-7.

24. Aviles D, Landi V, Delgado JV, Vega-Pla JL, Martinez A. Isolation and characterization of a dinucleotide microsatellite set for a parentage and biodiversity study in domestic guinea pig (Cavia porcellus). Ital J Anim Sci. 2015;14(4):615-20.

25. Maldonado-Chaparro A, Bernal-Parra LM, Forero-Acosta G, Ruiz-Garcia M. Estructura genética de un grupo de capibaras, Hydrochoerus hydrochaeris (Rodentia: Hydrocheridae) en los Llanos orientales colombianos. Rev Biol Trop. 2011;59(4):1777-933.

26. Herrera EA, Chemello ME, Lacey EA, Salas V, Sousa BF. Characterization of microsatellite markers from capybaras, Hydrochoerus hydrochaeris (Rodentia: Hydrochoeridae). Mol Ecol Notes. 2004;4(4):541-3.

27. DeMatteo KE, Rinas MA, Zurano JP, Selleski N, Schneider RG, Arguelles CF. Using niche-modelling and species-specific cost analyses to determine a multispecies corridor in a fragmented landscape. PLOS ONE. 2017;12(8):e0183648. https://doi.org/10.1371/journal.pone.0183648.

28. Ball MC, Pither R, Manseau M, Clark J, Peterson SD, Kingston S, et al. Characterization of target nuclear DNA from faeces reduces technical issues associated with the assumptions of low-quality and quantity template. Conserv Genet. 2007;8(3):577-86.

29. Rutledge LY, Holloway JJ, Patterson BR, White BN. An Improved Field Method to Obtain DNA for Individual Identification From Wolf Scat. J Wildl Manage. 2009;73(8):1430-5.

30. Sambrook J, Fritsch EF, Maniatis T. Molecular cloning: a Laboratory Manual. 2nd ed. Cold Spring Harbor: Cold Spring Harbor Laboratory Press; 1989

31. Rodgers TW, Janečka JE. Applications and techniques for noninvasive faecal genetics research in felid conservation. Eur J Wildl Res. 2013;59(1):1-16.

32. Palomares F, Godoy JA, Piriz A, O'Brien SJ. Faecal genetic analysis to determine the presence and distribution of elusive carnivores: design and feasibility for the Iberian lynx. Mol Ecol. 2002;11(10):2171-82.

33. Cossios ED, Madrid A, Condori JL, Fajardo U. Update on the distribution of the Andean cat Oreailurus jacobita and the pampas cat Lynchailurus colocolo in Perú. Endanger Species Res. 2007;3(3):313-20.

34. Fernandez N, Delibes M, Palomares F. Landscape evaluation in conservation: molecular sampling and habitat modeling for the Iberian lynx. Ecol Appl. 2006;16(3):1037-49.

35. Mukherjee S, Krishnan A, Tamma K, Home C, Navya R, Joseph S, et al. Ecology driving genetic variation: a comparative phylogeography of jungle cat (Felis chaus) and leopard cat (Prionailurus bengalensis) in India. PLoS ONE. 2010;5(10):e13724. https://doi.org/10.1371/journal.pone.0013724.

36. Farrell LE, Roman J, Sunquist ME. Dietary separation of sympatric carnivores identified by molecular analysis of scats. Mol Ecol. 2000;9(10):1583-90.

37. Walker RS, Novaro AJ, Perovic P, Palacios R, Donadio E, Lucherini M, et al. Diets of three species of Andean carnivores in high-altitude deserts of Argentina. J Mammal. 2007;88(2):519-25.

38. Bhagavatula J, Singh L. Genotyping faecal samples of Bengal tiger Panthera tigris tigris for population estimation: a pilot study. BMC Genet 2006;7(1):48.

39. Janečka JE, Jackson R, Yuquang Z, Diqiang L, Munkhtsog B, BuckleyBeason $\mathrm{V}$, et al. Population monitoring of snow leopards using noninvasive collection of scat samples: a pilot study. Anim Conserv. 2008:11(5):401-11.

40. Perez I, Geffen E, Mokady O. Critically endangered Arabian leopards Panthera pardus nimr in Israel: estimating population parameters using molecular scatology. Oryx. 2006;40(3):295-301.

41. Mondol S, Ullas-Karanth K, Samba-Kumar N, Gopalaswamy AM, Andheria A, Ramakrishnan U. Evaluation of non-invasive genetic sampling methods for estimating tiger population size. Biol Conserv. 2009;142(10):2350-60.
42. Ruell EW, Riley SPD, Douglas MR, Pollinger JP, Crooks KR. Estimating bobcat population sizes and densities in a fragmented urban landscape using noninvasive capture-recapture sampling. J Mammal. 2009;90(1):129-35.

43. Janečka J, Munkhtsog B, Jackson R, Naranbaatar G, Mallon D, Murphy W. Comparison of noninvasive genetic and camera-trapping techniques for surveying snow leopards. J Mammal. 2011;92(4):771-83.

44. Haag T, Santos AS, Sana DA, Morato RG, Cullen LJ, Crawshaw PGJ, et al. The effect of habitat fragmentation on the genetic structure of a top predator: loss of diversity and high differentiation among remnant populations of Atlantic Forest jaguars (Panthera onca). Mol Ecol. 2010;19(22):4906-21.

45. Ernest HB, Boyce WM, Bleich VC, May B, Stiver SJ, Torres SG. Genetic structure of mountain lion (Puma concolor) populations in California. Conserv Genet. 2003;4(3):353-66.

46. Napolitano C, Bennett M, Johnson WE, O'Brien SJ, Marquet PA, Barria I, et al. Ecological and biogeographical inferences on two sympatric and enigmatic Andean cat species using genetic identification of faecal samples. Mol Ecol. 2008;17(2):678-90.

47. Russello MA, Gladyshev E, Miquelle D, Caccone A. Potential consequences of a recent bottleneck in the Amur tiger of the Russian far east. Conserv Genet. 2004;5(5):707-13.

48. Sharma R, Stuckas H, Bhaskar R, Khan I, Goyal SP, Tiedemann R. Genetically distinct population of Bengal tiger (Panthera tigris tigris) in Terai Arc Landscape (TAL) of India. Mamm Biol. 2011;76(4):484-90.

49. Paetkau D. An empirical exploration of data quality in DNA-based population inventories. Mol Ecol. 2003;12(6):1375-87.

50. Taberlet P, Griffin S, Goossens B, Questiau S, Manceau V, Escaravage N, et al. Reliable genotyping of samples with very low DNA quantities using PCR. Nucleic Acids Res. 1996;24(16):3189-94.

51. Wasser SK, Houston CS, Koehler GM, Cadd GG, Fain SR. Techniques for application of faecal DNA methods to field studies of Ursids. Mol Ecol. 1997:6(11):1091-7.

52. Dakin EE, Avise JC. Microsatellite null alleles in parentage analysis. Heredity. 2004;93(5):504.

53. Salomón-Soto VM, Montiel JC, Matzumura PD, Paláez GV. Assessment of the genetic variability in the captive population of the volcano rabbit (Romerolagus diazi). Vet Méx. 2005;36(2):119-26.

54. Wu X, Wang Y, Zhou K, Zhu W, Nie J, Wang C, et al. Genetic variation in captive population of Chinese Alligator (Alligator simensis) revealed by random amplified polymorphic DNA (RAPD). Biol Conserv. 2002;106(3):435-41.

55. Wang YQ, Zhu WQ, Huang L, Zhou KY, Wang RP. Genetic diversity of Chinese alligator (Alligator sinensis) revealed by AFLP analysis: an implication on the management of captive conservation. Biodivers Conserv. 2006;15(9):2945-55

56. Hubert $\mathrm{S}$, Hedgecock D. Linkage maps of microsatellite DNA markers for the Pacific oyster Crassostrea gigas. Genetics. 2004;168(1):351-62.

57. Hedgecock D, Li G, Hubert S, Bucklin K, Ribes V. Widespread null alleles and poor cross-species amplification of microsatellite DNA loci cloned from the Pacific oyster Crassostrea gigas. J Shellfish Res. 2004;23(2):379-86.

58. Mills LS, Citta JJ, Schwarz KP, Tallman DA. Estimating animal abundance using non-invasive DNA sampling: promise and pitfalls. Ecol Appl. 2000;10(1):283-94.

\section{Publisher's Note}

Springer Nature remains neutral with regard to jurisdictional claims in published maps and institutional affiliations. 